\title{
The Welfare Effects of a Large Depreciation: The Case of Egypt, 2000-05
}

\author{
Aart Kraay \\ The World Bank
}

\begin{abstract}
The Egyptian pound depreciated sharply between 2000 and 2005, declining by 26 percent in nominal trade-weighted terms. This paper investigates the effect of the large depreciation on household welfare operating through exchange rate-induced changes in consumer prices. I estimate exchange rate pass-through regressions using disaggregated monthly consumer price indices to isolate the impact of the exchange rate changes on consumer prices. I then use household-level data from the 2000 and 2005 Egyptian household surveys to quantify the welfare effects of these consumer price changes at the household level. The average welfare loss due to exchange rateinduced price increases was equivalent to 7.4 percent of initial expenditure. Stronger estimated exchange rate pass-through for food items imply that this effect disproportionately impacted poorer households.
\end{abstract}

\section{World Bank Policy Research Working Paper 4182, April 2007}

The Policy Research Working Paper Series disseminates the findings of work in progress to encourage the exchange of ideas about development issues. An objective of the series is to get the findings out quickly, even if the presentations are less than fully polished. The papers carry the names of the authors and should be cited accordingly. The findings, interpretations, and conclusions expressed in this paper are entirely those of the authors. They do not necessarily represent the view of the World Bank, its Executive Directors, or the countries they represent. Policy Research Working Papers are available online at http://econ.worldbank.org.

1818 H Street N.W, Washington, DC, 20433, akraay@worldbank.org, http://econ.worldbank.org/staff/akraay. This paper was prepared as background for the 2007 Egypt Poverty Assessment. I would like to thank without implication Sherine El-Shawarby, Heba El-Laithy, Faika El-Refaie, Francisco Ferreira, Jed Friedman, Michael Lokshin, Martin Ravallion, Luis Serven, and conference participants at the Egyptian Center for Economic Studies for helpful discussions. 


\section{Introduction}

Between 2000 and 2005 Egypt experienced a large nominal depreciation of the Egyptian pound, much of it concentrated around a sharp devaluation in early 2003 . The objective of this paper is to assess the welfare implications of the large changes in consumer prices that accompanied this movement in the exchange rate. To address this issue I first need to isolate the component of observed price changes during this period that are due to the depreciation. I do this by estimating disaggregated exchange rate pass-through regressions, using monthly consumer price index $(\mathrm{CPI})$ data over the period July 2000 through June 2005, for 8 regions in Egypt, disaggregated into 20 different goods and services. ${ }^{1}$ The fitted values from these regressions provide estimates of the effect of the depreciation on 160 different price indices. Disaggregation of exchange rate pass-through to this level is important, as there is considerable heterogeneity across commodities in the response of domestic consumer prices to the exchange rate. In particular, I find that on average, exchange rate pass-through was greater for food items than for non-food items, and even within food items varied considerably. Regional variation in pass-through is also present, but is not as large as across consumption items.

I then bring the estimated price changes due the depreciation for each of these 160 different price indices to the household survey for Egypt, to investigate their welfare effects. I empirically construct estimates of the compensating variation associated with these price changes for each household. In particular, I estimate how much higher (or lower) each household's total expenditure would have to be in order to attain the predepreciation level of utility at post-depreciation prices. ${ }^{2}$ This compensating variation consists of two parts. The first is the change in the cost of households' initial

\footnotetext{
${ }^{1}$ The regions are dictated by the disaggregation available in the CPI data, and are Cairo, Alexandria, Canal, Border, Upper and Lower Urban, and Upper and Lower Rural. The commodity disaggregation is dictated by overlap between expenditure categories in the household survey and the CPI data.

${ }^{2}$ See Friedman and Levinsohn (2002) for a similar exercise investigating the welfare effects of relative price changes following in Indonesia during the East Asian crisis of 1997. The main difference with this paper is that they do not estimate exchange rate pass-through to consumer prices, but, reasonably enough in the case of the enormous depreciation of the rupiah, assume that all of observed price changes were due to the depreciation. Ferreira et. al. (2004) study the distributional consequences of a large depreciation in Brazil, using a sectorally-disaggregated macro model to quantify the effects of the depreciation on wages and prices, and then linking this to a household survey.
} 
consumption bundles as a result of depreciation-induced price changes. The second captures changes in household behavior in response to these price changes. A modest methodological contribution of this paper is to show how these substitution effects can be estimated easily given the (pseudo-) panel dimension of the data that I have for Egypt. I find that most of the compensating variation is captured by the direct effect, which averages 7.4 percent of initial expenditure, and is statistically significantly (although quantitatively modestly) higher in poorer households. I find that there is a great deal of heterogeneity across households in the estimated size of the welfare effect of the depreciation. Most of this heterogeneity is due to differences in consumption patterns across households. A policy implication of this heterogeneity is that it would be difficult to accurately target any kind of subsidy program to offset the effects of the depreciation.

Three major qualifications regarding these results should be kept in mind. First, a significant limitation of this paper is that I am only able to study the welfare effects of depreciation-induced changes in consumer prices. The depreciation is likely to have had heterogenous effects on the incomes of different households as well. With imperfect labour mobility, for example, it is plausible that households employed in exporting sectors would have seen increases in earnings, while household employed in import-competing industries would have seen declines in earnings, as a result of the depreciation. Unfortunately, however, the Egyptian household survey data that I use provide only very limited information on the economic sector of employment, and so I cannot investigate these kind of effects, and their distributional consequences, in any detail. $^{3}$

A second limitation is the fairly coarse level of aggregation at which I am able to estimate the exchange-rate induced component of price changes. As discussed further below, by working at this coarse level of aggregation, I am likely to be underestimating the scope that households have for adjusting their expenditure patterns in response to price changes. This in turn means that I am likely to be overestimating the adverse

\footnotetext{
${ }^{3}$ See Ravallion and Chen (2004) for an effort to look at the effects of relative price changes on household consumptions and incomes, in the case of China, and Ferreira et. al. (2004) for the case of Brazil.
} 
welfare effect of the depreciation, which could be substantially smaller than what is reported here.

Third, I stress that I am looking at the welfare effects of depreciation-induced changes in consumer prices over a fairly short period with a fairly large depreciation, and this time horizon drives the finding of significant welfare losses. However, looking at exchange rate changes over other horizons would naturally lead to different conclusions. For example, the depreciation in the trade-weighted nominal exchange rate between 2000 and 2005 was preceded by an even larger trade-weighted nominal appreciation in the previous five years between 1995 and 2000. In fact, for the entire period between 1995 and 2005, the trade-weighted nominal exchange rate appreciated by about 20 percent. If the pattern of exchange rate pass-through to disaggregated consumer prices was similar during this earlier period, then one can interpret the welfare losses sustained between 2000 and 2005 as just a partial reversal of the welfare gains experienced during the appreciation between 1995 and 2000.

\section{The Depreciation and Consumer Price Changes}

Figure 1 shows the evolution of the nominal exchange rate and consumer price index in Egypt between 1995 and 2005. The pound was fixed against the US dollar between 1995 and 1999, followed by a moderate depreciation during 2000 and 2001. In 2002 the pound was again fixed against the US dollar, but during 2003 it depreciated sharply by 31 percent against the dollar, and by 41 percent in trade-weighted terms. ${ }^{4}$ The consumer price index increased by 6.2 percent during 2003 and by another 10.8 percent during 2004. As shown in Table 1, the trade-weighted exchange rate

\footnotetext{
${ }^{4}$ The trade-weighted exchange rate index used here is constructed using data from Egypt's 25 largest trading partners in 2000. I use fixed weights based on these countries' shares in Egypt's imports in 2000. During this period there were some exchange controls in place and the parallel exchange vis-a-vis the US dollar diverged significantly from the official rate (in levels). This raises the question of whether it is more appropriate to use the parallel market rate. For the analysis that follows, what matters is the exchange rate at which importers actually transact. If they have access to foreign currency at official (parallel) rates then the official (parallel) rates are appropriate. Absent information on this, and absent data on parallel rates vis-a-vis all trading partners, I use the trade-weighted official rates. However, in unreported results I obtain very similar estimates of pass-through using the parallel market rate vis-a-vis the US dollar. This because although the two series diverge somewhat in levels, in differences they track each other quite closely over the period I consider.
} 
depreciated cumulatively by 26.2 percent between 2000 and 2005, and the exchange rate vis-a-vis the dollar depreciated by 52.2 , while consumer prices rose by 27.6 .

The key question I address in this section is the effect of the large depreciation during 2003 on disaggregated consumer prices. Table 2 reports the cumulative growth rate between July 2000 and June 2005 of the disaggregated components of the consumer price index that I have for Egypt. ${ }^{5}$ A quick glance at this table reveals that price changes have varied considerably across expenditure items, and to a lesser extent across regions. Most striking is the behavior of food prices, which increased faster than the overall consumer price index. Taking a simple average across regions, overall consumer prices increased by 28 percent, but food prices increased by 38 percent, implying a 10 percent increase in the relative price of food. In the remainder of this section I investigate in detail the contribution of the depreciation of the Egyptian pound to these absolute and relative price changes.

\subsection{Empirical Framework}

As shown in Table 2, I have monthly data on the consumer price index disaggregated into 31 goods and services, for 8 regions in Egypt. Because of difficulties in mapping the expenditure items in the CPI to the household survey, I will work with a somewhat more aggregated set of 20 of these expenditure items that correspond to expenditure categories in the household survey. I model the consumer price of item i in region $r$ in month $t$ as follows:

$$
P_{\text {irt }}=\left(P_{\text {irt }}^{N}\right)^{\alpha_{\text {ir }}} \cdot\left(P_{\text {irt }}^{T}\right)^{1-\alpha_{\text {ir }}}
$$

where $\mathrm{P}^{\mathrm{N}}$ denotes the price of the non-traded component and $\mathrm{P}^{\top}$ denotes the price of the traded component of that item. To simplify notation, we can think of the non-traded component as capturing both purely non-traded goods within this item, as well as nontraded distribution costs associated with the traded goods. Accordingly we can think of $\mathrm{P}^{\top}$ as the price of imported goods "on the dock" in Egypt. Concretely, one of our disaggregated items is fruit. $\mathrm{P}^{\top}$ would therefore be the price of imported fruit "on the

\footnotetext{
${ }^{5}$ We would like to thank the staff of CAPMAS for kindly assembling this dataset.
} 
dock", while $\mathrm{P}^{\mathrm{N}}$ is a price index of non-traded fruit as well as the distribution costs associated with both kinds of fruit.

Following the large empirical literature on exchange rate pass-through, I model the logarithm of this import price as a linear function of the log exchange rate and a measure of foreign marginal costs of production: ${ }^{6}$

$$
\ln P_{\text {irt }}^{\top}=\beta_{0 \text { ir }}+\beta_{\text {1ir }}(L) \cdot \ln E_{t}+\beta_{2 \text { ir }}(L) \cdot \ln C_{t}+u_{\text {irt }}
$$

where $E$ is the exchange rate, $C$ is a proxy for foreign marginal costs, and $u$ is an error term that I assume is independent of the exchange rate. I do not have any direct measure of foreign marginal costs of production disaggregated by product. I therefore simply introduce an aggregate foreign cost variable, which is a trade-weighted average of the monthly producer price index in Egypt's five largest trading partners for which this data exist. ${ }^{7}$ Note that I allow the extent of foreign cost pressures on export prices to vary by product and region. $\beta_{1}(\mathrm{~L})$ and $\beta_{2}(\mathrm{~L})$ are polynomials in the lag operator, so that I allow current and lagged values of the exchange rate and foreign costs to affect import prices in order to capture slow adjustment.

Taking log differences of (1) and using (2) gives the growth rate of the consumer price as a function of the growth rate of the exchange rate:

$$
\Delta \ln P_{\text {irt }}=\alpha_{i r} \cdot \Delta \ln P_{i r t}^{N}+\left(1-\alpha_{i r}\right) \cdot\left(\beta_{0 i r}+\beta_{1 i r}(L) \cdot \Delta \ln E_{t}+\beta_{2 i r}(L) \cdot \Delta \ln C_{t}+\Delta u_{i r t}\right)
$$

The effect of current and lagged changes in the exchange rate on consumer prices is given by $\left(1-\alpha_{\mathrm{ir}}\right) \cdot \beta_{\mathrm{ir}}(\mathrm{L})$, and this is the key parameter of interest for this section. It is important to note that the sensitivity of consumer prices to the exchange rate is likely to be substantially smaller than the sensitivity of border prices to the exchange rate. This is because consumer prices contain a substantial non-traded component, both in the form

\footnotetext{
${ }^{6}$ See for example Campa and Goldberg (2005) for a justification of this particular specification. Burstein, Eichenbaum and Rebelo (2005) document the importance of non-traded components of traded goods prices and their role in real exchange rate fluctuations.

${ }^{7}$ These are the United States, Germany, Italy, Great Britain, and Japan. Saudi Arabia and France are among Egypt's top 5 sources of imports in 2000 but do not report monthly producer price indices.
} 
of non-traded items themselves, as well as distribution costs. I do not have direct information on the size of these distribution margins in the case of Egypt, although in principle these can be extracted from input-output tables for Egypt. In industrial countries, these distribution margins are typically quite substantial, averaging 30-50 percent of the prices paid by consumers (Campa and Goldberg (2006)).

Unfortunately, however, I cannot simply estimate Equation (3) econometrically since I do not directly observe the price of the non-traded component of each good, $\mathrm{P}^{\mathrm{N}}$. I also cannot ignore this term and treat it as part of the error term in a regression since movements in the non-traded component of goods prices might be spuriously correlated with movements in the exchange rate. In particular, during much of the period of interest there were across-the-board increases in nominal prices in Egypt together with a depreciation in the exchange rate, and at least part of these price increases were likely driven by purely domestic factors.

To address this problem I assume that the growth rate of the non-traded component of the price of each item in each region consists of a common component and an idiosyncratic component that is orthogonal to movements in the exchange rate:

$$
\Delta \ln P_{\mathrm{irt}}^{N}=\Delta \ln \mathrm{P}_{\mathrm{rt}}^{\mathrm{N}}+\mathrm{v}_{\mathrm{irt}}
$$

I assume further that I can approximate the common component of non-traded goods prices with a simple average of a few items in the consumer price index that appear to be primarily non-traded on a priori grounds. These are Domestic Services, and Restaurant and Hotel Services. ${ }^{8}$ These two assumptions (of a common component in non-traded goods prices, approximated by these two particular prices) are clearly strong ones and open to debate. However, it is not clear what good alternatives might be available. Although the results that follow are based on this assumption, I have tried three alternatives, and found that the estimates of pass-through are not very different. One possibility is to try to model explicitly purely domestic sources of inflation, for example by including measures of growth in the money supply in the regression. I

\footnotetext{
${ }^{8}$ Other clearly largely-non-traded items are rent and education. However prices of these items are tightly controlled in Egypt and movements in them are unlikely to properly reflect movements in overall non-traded goods prices.
} 
experimented with this but found it difficult to obtain reasonable estimates of the effect of money growth on disaggregated consumer prices. Another possibility is to simply allow for a time trend in the regression for each good, to capture the upward trend in domestic prices during the period. A third possibility is to simply ignore the domestically-induced changes in non-traded goods prices and drop them from the regressions.

In any case, denoting the growth rate of the simple average of these items in each region as $\Delta \ln \hat{P}_{\mathrm{rt}}^{N}$, I obtain the following empirical specification:

$$
\Delta \ln P_{\text {irt }}=\gamma_{\text {oir }}+\gamma_{\text {ir }}(L) \cdot \Delta \ln E_{t}+\gamma_{2 i r}(L) \cdot \Delta \ln C_{t}+\gamma_{3 i r} \cdot \Delta \ln \hat{P}_{r t}^{N}+e_{i r t}
$$

where $\gamma_{\text {oir }}=\left(1-\alpha_{\text {ir }}\right) \cdot \beta_{\text {oir }}$ is the intercept; $\gamma_{\text {ir }}(L)=\left(1-\alpha_{\text {ir }}\right) \cdot \beta_{\text {ir }}(L)$ captures the effect of the exchange rate on consumer prices; $\gamma_{2 \text { ir }}(L)=\left(1-\alpha_{\text {ir }}\right) \cdot \beta_{2 \text { ir }}(L)$ captures the effect of foreign costs on consumer prices; $\gamma_{3 i r}=\alpha_{i r}$ captures the contribution of changes in nontraded goods prices; and $\mathrm{e}_{\mathrm{irt}}=\alpha_{\mathrm{ir}} \cdot \Delta \mathrm{v}_{\mathrm{irt}}+\left(1-\alpha_{\mathrm{ir}}\right) \cdot \Delta \mathrm{u}_{\mathrm{irt}}$ is the error term. Since this composite error term is by assumption uncorrelated with the right-hand-side variables, I can estimate Equation (5) by ordinary least squares. In practice, I measure all growth rates as monthly observations on quarterly log differences, and I allow for 3, 6, and 9 month lags of these growth rates in the estimation. Since I have monthly data from July 2000 through July 2005 this gives me 60 monthly data points on which to estimate this specification for each item and region.

\subsection{Results}

I first calculate the long-run pass-through coefficient as the sum of the coefficients on the current and lagged exchange rate variables, i.e. $\hat{\gamma}_{1 \mathrm{ir}}(1)$, for each of the 160 product-region combinations for which I have data. Figure 2 provides a visual summary of the pass-through estimates, and Table 3 reports some summary statistics. In the top panel of the graph I report pass-through estimates for some aggregate categories, and in the bottom panel I report estimates for disaggregated food items. I organize the pass-through estimates by product, and use box-plots to show the distribution across the 8 regions of our estimates of pass-through for each product. In 
Figure 3 I generate the same box-plots by product category, but now reporting the tstatistics associated with the test of the hypothesis that the long-run pass-through coefficient is zero. There are several striking features of these two figures and table:

- Estimates of the long-run impact of the exchange rate on consumer prices are quite substantial for many products. The median long-run estimated passthrough effect was 19 percent, indicating that 19 percent of the movement in the trade-weighted exchange rate was reflected in consumer prices. Many of the estimated pass-through coefficients are much higher, with the 75th percentile equal to 47 percent pass-through.

- Estimates of pass-through vary substantially across products. The most notable difference is between food and non-food items, with much higher estimates of pass-through for food items. In particular, pooling all regions, the median estimate of pass-through for food items is 0.43 , while for non-food items it is only 0.07 (see the second column of Table 3). In the top panel of Figure 2, the passthrough estimates for an aggregate price index for food, beverages, and tobacco are clearly much higher than for other non-food categories shown. This is true also for many individual food products as shown in the bottom panel of Figure 2.

- Estimates of pass-through are in most cases very statistically significant. This can be seen in Figure 3 which reports the distribution of t-statistics associated with the null hypothesis that the long-run estimated pass-through effect is zero. For almost all food items, and for some non-food items, these t-statistics are quite large indicating highly significant estimates. For several non-food items, however, estimated pass-through effects are not significantly different from zero, and in some cases are even negative (peculiarly, for entertainment, the estimates are significantly negative). As these negative pass-through estimates are difficult to interpret, I will set them to zero in the subsequent analysis of welfare effects.

Unfortunately, there are few studies of exchange rate pass-through to disaggregated consumer prices in developing countries to which we can compare these results. Campa and Goldberg (2006) study a sample of 21 OECD countries and document that the median (across countries) pass-through of the exchange rate to the consumer price index is 17 percent, which is quite similar to the median (across goods) 
pass-through estimates reported here for Egypt. Choudri and Hakura (2001) estimate exchange rate pass-through to the aggregate CPI in a sample of 71 developed and developing countries. They find an average long-run pass-through of 35 percent in a group of moderate-inflation countries including Egypt, and 24 percent for Egypt itself, which is slightly higher than the median (across commodities) estimate reported above. Frankel, Parsley and Wei (2005) report a substantially higher estimate of pass-through of 42 percent for a set of eight very specific branded commodities, pooling data from a sample of 76 developed and developing countries. However, several of the commodities they consider are food, alcohol and tobacco products, and in the case of Egypt I find substantially higher pass-through for such commodities.

The estimated change in consumer prices due to the depreciation can be obtained by multiplying the pass-through estimates by the observed change in the exchange rate. Between 2000 and 2005, the trade-weighted exchange rate that I use depreciated by 26.2 percent (see last column of Table 1). I therefore multiply the estimates of pass-through reported in Figure 2 by 26.2 percent to obtain the estimated change in consumer prices due to the depreciation. To take a specific example, the estimate of pass-through for Meat and Poultry in Cairo is 0.43 , implying that the depreciation increased the price of this product category in Cairo by 11 percent. The actual change in the price of Meat and Poultry in Cairo was 43 percent, so that roughly one-quarter of the observed increase in the price of this item in Cairo was due to the depreciation.

More systematically, I calculate the ratio of the exchange-rate induced change in each price to the actual observed price change for each of the 20 goods in eight regions in Egypt, and summarize these ratios using boxplots in Figure 4, while the last column of Table 3 reports summary statistics. For the median consumption item, 19 percent of the observed growth in nominal prices can be attributed to the depreciation, with an interquartile range from 6 percent to 34 percent. Since the estimated pass-through coefficients are substantially bigger for food than for non-food items, our estimates of the exchange rate-induced price changes are also much bigger for food items, where the median is 31 percent, as opposed to 10 percent for non-food items. 
These higher rates of pass-through for food items give a first indication of the distributional consequences of the depreciation. Since poorer households devote a greater share of expenditure to food items, the price changes associated with the depreciation would have had a larger effect on them. In the next section of the paper I turn documenting in more detail the welfare effects of these price changes.

\section{Estimating the Welfare Impact of Exchange Rate Induced Price Changes}

The next step is to take the estimates of the changes in prices induced by movements in the exchange rate and calculate their welfare effects.

\subsection{Empirical Framework}

I use the compensating variation as a standard measure of welfare effects of price changes. In particular, let $e(u, p)$ denote the expenditure function, i.e.

$$
e\left(p, u^{*}\right) \equiv \min p^{\prime} x \quad \text { s.t. } u(x)>u^{*}
$$

where $p$ is an $n \times 1$ vector of prices, $x$ is an $n \times 1$ vector of quantities demanded, $u(x)$ is a well-behaved utility function, and $u^{*}$ is a reference level of utility. Let $p_{0}$ denote the reference prices prevailing in 2000 , the time of the initial household survey, and let $\Delta \mathrm{p} \equiv \mathrm{p}_{1}-\mathrm{p}_{0}$ denote the vector of price changes that were caused by the depreciation between 2000 and 2005, that I have isolated empirically in the previous section. The compensating variation measures the change in expenditure that would be required in order for households to achieve their pre-depreciation utility $\mathrm{u}^{\star}$ at the post-depreciation set of prices, $p_{1}$ :

$$
c v=e\left(p_{1}, u^{*}\right)-e\left(p_{0}, u^{*}\right)
$$

I will empirically approximate the compensating variation using a second-order Taylor expansion of the expenditure function around the initial period prices: ${ }^{9}$

\footnotetext{
${ }^{9}$ This approach is also taken by Levinsohn and Friedman (2002). An alternative is Vartia (1983), who shows how to get the exact comparison of utility in time 0 and time 1 , by numerically
} 


$$
\mathrm{cv} \approx \Delta \mathrm{p}^{\prime} \frac{\partial \mathrm{e}\left(\mathrm{p}, \mathrm{u}^{*}\right)}{\partial \mathrm{p}}+\frac{1}{2} \Delta \mathrm{p}^{\prime} \frac{\partial^{2} \mathrm{e}\left(\mathrm{p}, \mathrm{u}^{\star}\right)}{\partial \mathrm{p} \partial \mathrm{p}^{\prime}} \Delta \mathrm{p}
$$

where the matrices of first and second derivatives of the expenditure function are evaluated at $\mathrm{p}_{0}$. Using Shephard's Lemma and the fact that compensated and ordinary demands are equal at the initial optimal allocation, I can write this approximation to the compensating variation as a share of initial expenditure $e_{0}$ as:

$$
\frac{c v}{\mathrm{e}_{0}} \approx \frac{\Delta \mathrm{p}^{\prime} \mathrm{x}_{0}}{\mathrm{e}_{0}}+\frac{1}{2 \cdot \mathrm{e}_{0}} \Delta \mathrm{p}^{\prime} \frac{\partial \mathrm{h}\left(\mathrm{p}, \mathrm{u}^{\star}\right)}{\partial \mathrm{p}^{\prime}} \Delta \mathrm{p}
$$

where $h\left(p, u^{\star}\right)$ is the Hicksian or compensated demand function.

The interpretation of this expression is straightforward. The first term captures direct effect of price changes, which is just the change in the cost of purchasing the initial consumption bundle, $x_{0}$, expressed as a share of initial total expenditure, $e_{0}$. In particular I can write the direct effect of the price changes in proportional terms as:

$$
\frac{\Delta \mathrm{p}^{\prime} \mathrm{x}_{0}}{\mathrm{e}_{0}}=\sum_{\mathrm{i}} \mathrm{w}_{\mathrm{i}} \cdot \frac{\Delta \mathrm{p}_{\mathrm{i}}}{\mathrm{p}_{\mathrm{i}}}
$$

where $w_{i}=\frac{p_{i 0} \cdot x_{i 0}}{e_{0}}$ is the share of good $i$ in initial total spending and $\frac{\Delta p_{i}}{p_{i}}$ is the proportional change in the price of good i. Thus, the direct effect of the price changes, as a share of initial expenditure, is just a weighted average of the growth rate of the prices of each good, with weights equal to the initial expenditure shares.

Considering only this direct effect would overstate the welfare effect of the price changes because it does not take into account how households change their spending patterns in response to price changes. If households can substitute away from goods 
that become relatively more expensive, then the direct effect of the price changes will exaggerate the welfare effects since it assumes no such substitution is possible.

Estimating these substitution effects is therefore important, although substantially more involved. One direct approach is to econometrically estimate a demand system over the n consumption goods, using data from the household survey, and retrieve from this an estimate of the matrix of price derivatives of the compensated demand function, $\frac{\partial \mathrm{h}}{\partial \mathrm{p}^{\prime}}$.

Doing so however requires data on goods prices at the household level. In the case of the Egyptian household survey, I have some information on unit values for individual consumption items. However, at the more aggregated level at which the exchange rate pass-through estimates are calculated, these unit values become very difficult to interpret. $^{10}$

In this paper I take a different and computationally much simpler approach that exploits the fact that I have two household surveys for Egypt, for 2000 and 2005. The basic idea is to use information on observed changes in expenditure shares over this period to back out estimates of the substitution effects. The key simplification of this approach is that it obviates the need to estimate an entire demand system, but instead requires only estimates of the expenditure elasticities for each consumption item. As long as prices faced by individual households are orthogonal to total expenditure, these elasticities can be estimated by simple regressions of expenditure shares on total expenditure alone.

To implement this idea, I first need to relate observed changes over time in quantities demanded to the substitution effects of interest. Taking a first-order approximation to changes in the observed ordinary demand function I have:

$$
\Delta x(p, e) \approx \frac{\partial x(p, e)}{\partial p^{\prime}} \Delta p^{*}+\frac{\partial x(p, e)}{\partial e} \Delta e
$$

where $x(p, e)$ is the ordinary demand function; $\Delta x(p, e)$ are the changes in quantities demanded between 2000 and 2005; and $\Delta p^{*}$ is the vector of overall price changes

${ }^{10}$ Friedman and Levinsohn (2002) implement an approach originally due to Deaton $(1988,1990)$ who shows how to estimate demand systems when only unit value data are available. 
between 2000 and 2005. Note that $\Delta p^{*}$ refers to overall price changes during this period, while $\Delta \mathrm{p}$ above refers only to the depreciation-induced component of price changes. Next I can use the Slutsky equation, which express the observable elasticities of the ordinary demand function in terms of the unobserveable elasticities of the compensated demand function, i.e.

$$
\frac{\partial x(p, e)}{\partial p^{\prime}}=\frac{\partial h(p, u)}{\partial p^{\prime}}-\frac{\partial x(p, e)}{\partial e} x(p, e)^{\prime}
$$

Substituting Equation (12) into Equation (11) and rearranging results in:

$$
\frac{\partial h(p, u)}{\partial p^{\prime}} \Delta p^{*} \approx \Delta x(p, e)-\frac{\partial x(p, e)}{\partial e} \Delta x(p, e)^{\prime} p
$$

Suppose momentarily that we were interested in evaluating the welfare effects of the full set of price changes between 2000 and 2005, i.e. $\Delta \mathrm{p}^{\star}$, as opposed to simply those price changes induced by the depreciation, i.e. $\Delta$ p. Then I could simply pre-multiply Equation (13) by $\Delta \mathrm{p}^{\star \prime}$ and I would have the substitution component of the compensating variation on the left-hand-side, expressed in terms of observables on the right-hand side. In particular, on the right-hand side of Equation (13) I have observed changes in quantities demanded, $\Delta x$, and the derivatives of demand with respect to total expenditure, $\frac{\partial x}{\partial \mathrm{e}}$, that can readily and easily be estimated from available data on expenditure shares and total expenditure at the household level.

Unfortunately, however, things are more complicated in this case since I want to obtain an estimate of substitution effects in response to depreciation-induced price changes, $\Delta p^{\prime} \frac{\partial h(p, u)}{\partial p^{\prime}} \Delta p$, not substitution effects in response to overall price changes, $\Delta p^{* \prime} \frac{\partial h(p, u)}{\partial p^{\prime}} \Delta p^{*}$. In order to make progress, I make one further, and non-trivial 
assumption, that the Slutsky matrix $\frac{\partial h}{\partial p^{\prime}}$ is diagonal, i.e. that all compensated cross-price elasticities are zero. In this case, Equation (13) simplifies to:

$$
\left(\frac{\partial \mathrm{h}_{\mathrm{i}}}{\partial \mathrm{p}_{\mathrm{i}}} \cdot \frac{\mathrm{p}_{\mathrm{i}}}{\mathrm{h}_{\mathrm{i}}}\right) \cdot \frac{\Delta \mathrm{p}_{\mathrm{i}}^{*}}{\mathrm{p}_{\mathrm{i}}} \approx \frac{\Delta \mathrm{x}_{\mathrm{i}}}{\mathrm{x}_{\mathrm{i}}}-\left(\frac{\partial \mathrm{x}_{\mathrm{i}}}{\partial \mathrm{e}} \cdot \frac{\mathrm{x}_{\mathrm{i}}}{\mathrm{e}}\right) \cdot \sum_{\mathrm{j}} \mathrm{w}_{\mathrm{j}} \cdot \frac{\Delta \mathrm{x}_{\mathrm{j}}}{\mathrm{x}_{\mathrm{j}}}
$$

Given estimates of the expenditure elasticities $\left(\frac{\partial x_{i}}{\partial e} \cdot \frac{x_{i}}{e}\right)$ I can solve (14) for the compensated own-price elasticities $\left(\frac{\partial h_{i}}{\partial p_{i}} \cdot \frac{p_{i}}{h_{i}}\right)$. Finally, I can substitute these into Equation (9) to obtain the following estimate of the substitution effect:

$$
\frac{1}{2 \cdot \mathrm{e}_{0}} \Delta \mathrm{p}^{\prime} \frac{\partial \mathrm{h}\left(\mathrm{p}, \mathrm{u}^{\star}\right)}{\partial \mathrm{p}^{\prime}} \Delta \mathrm{p} \approx \frac{1}{2} \cdot \sum_{\mathrm{i}} \mathrm{w}_{\mathrm{i}} \cdot\left(\frac{\partial \mathrm{h}_{\mathrm{i}}}{\partial \mathrm{p}_{\mathrm{i}}} \cdot \frac{\mathrm{p}_{\mathrm{i}}}{\mathrm{h}_{\mathrm{i}}}\right) \cdot\left(\frac{\Delta \mathrm{p}_{\mathrm{i}}}{\mathrm{p}_{\mathrm{i}}}\right)^{2}
$$

Clearly the assumption of a diagonal Slutsky matrix is a restrictive and unappealing one. However, as I discuss later, we shall see that estimated substitution effects for the full set of price changes $\Delta \mathrm{p}^{*}$, which do not require this restriction, are quite similar in magnitude to the estimated substitution effects associated with the exchangerate induced changes in consumer prices. This gives some comfort that this assumption is not too misleading. Moreover, it is worth remembering that this restriction does not imply that the cross-price elasticities of ordinary demands are zero. Rather, it restricts the effect of changes in the price of good $i$ on the quantity demanded of good $j$ to operate through the income effect of the change in the price of good $j$ (i.e. the price change multiplied by the initial spending share), multiplied by the income elasticity of good j.

\subsection{Results}

I begin by reporting estimates of the direct effects of price changes, that I summarize in Figure 5, graphing the estimated compensating variation on the vertical 
axis against log total household expenditure on the horizontal axis. In particular, these direct effects are calculated for each household as the sum across all expenditure items of initial spending shares times the percentage change in the price of each item due to the depreciation, setting negative pass-through estimates to zero. We shall see shortly that our estimates of the substitution effect are generally quite small, and so it makes sense to focus on the direct effects first. Several observations based on this graph:

- The estimated compensating variation is non-trivial for the vast majority of households. The income loss associated with the direct effect of exchange-rate induced price changes for the median household is 7.4 percent of initial expenditure. The 5th and 95th percentiles of the distribution of compensating variations at the household level are 4.9 and 9.9 percent of initial expenditure, respectively.

- The estimated compensating variation is significantly higher for poorer households, although the magnitude of the effect is modest. A simple regression of the compensating variation on log total expenditure gives a slope coefficient of -0.01. Since the log-difference in total expenditure between households at the 95th and 5th percentile of the expenditure distribution is about 2, this implies that the estimated real income loss due to the depreciation is about two percentage points of initial expenditure higher at the 5th percentile of the income distribution than at the 95th percentile. Controlling for household characteristics (log age and sex of household head and log household size) and regional effects raises the slope coefficient to -0.016 , implying a 3.2 percentage point difference in the income effect of the depreciation between rich and poor households. This adverse distributional effect of the depreciation is consistent with our finding that pass-through for food items was higher than for non-food items, coupled with the observation that the share of food in total expenditure is higher for poorer households.

- There is enormous heterogeneity across households in the size of the estimated compensating variation. A simple regression of the compensating variation on log total expenditure delivers an R-squared of only 17 percent. Including household characteristics and regional dummies raises this to 38 percent, leaving the majority of the cross-household variation in the estimated compensating variation unexplained. In the case of Indonesia, Friedman and 
Levinsohn (2002) find even greater heterogeneity, with similar regressions explaining only 11 (26) percent of the variation across rural (urban) households in the estimated compensating variation.

Figure 6 disaggregates the direct effect of the price changes by rural and urban households. To construct this figure I order households from poorest to richest within rural and urban areas. I then construct a rolling average over 100 households of the estimated compensating variation, and plot it against the percentile rank of the middle household of each group in the entire combined rural and urban expenditure distribution. Over most of the income distribution (and particularly from the 20th percentile on up) the rural compensating variation is slightly higher than for urban households. This figure also shows that the relationship between the compensating variation and income levels is fairly flat over most of the range of the expenditure distribution, and tails off sharply for the richest 10 percent or so of (mostly urban) households. It is also worth noting the estimates of the compensating variation for rural households is likely to be overstated relative to urban households. This is because rural household's net consumption of food items is likely smaller than their gross consumption when compared with urban households, and the depreciation in the exchange rate disproportionately increased food prices.

Table 4 reports the mean and standard deviation of the compensating variation by region and by quintile of the expenditure distribution. Regionally, the estimated compensating variation ranges from a low of 6.7 percent in the Border region to a high of 8.4 percent in Rural Lower Egypt. Within each region the estimated compensating variation declines as we move to successively higher quintiles of the expenditure distribution.

I next investigate further why there is so much heterogeneity across households in the estimated direct effect of depreciation-induced price changes, with the help of a simple decomposition exercise. Adding household subscripts h in Equation (10), I can decompose the direct component of the compensating variation for each household as follows: 


$$
\begin{aligned}
\frac{\Delta \mathrm{p}_{\mathrm{h}}{ }^{\prime} \mathrm{x}_{\mathrm{oh}}}{\mathrm{e}_{\mathrm{oh}}} & =\sum_{\mathrm{i}} \mathrm{w}_{\mathrm{ih}} \cdot \frac{\Delta \mathrm{p}_{\mathrm{ih}}}{\mathrm{p}_{\mathrm{ih}}} \\
& =\sum_{\mathrm{i}} \overline{\mathrm{w}}_{\mathrm{i}} \cdot \frac{\overline{\Delta \mathrm{p}_{\mathrm{i}}}}{\mathrm{p}_{\mathrm{i}}}+\sum_{\mathrm{i}} \overline{\mathrm{w}}_{\mathrm{i}} \cdot\left(\frac{\Delta \mathrm{p}_{\mathrm{ih}}}{\mathrm{p}_{\mathrm{ih}}}-\frac{\overline{\Delta \mathrm{p}_{\mathrm{i}}}}{\mathrm{p}_{\mathrm{i}}}\right) \\
& +\sum_{\mathrm{i}}\left(\mathrm{w}_{\mathrm{ih}}-\overline{\mathrm{w}}_{\mathrm{i}}\right) \cdot \frac{\overline{\Delta \mathrm{p}_{\mathrm{i}}}}{\mathrm{p}_{\mathrm{i}}}+\sum_{\mathrm{i}}\left(\mathrm{w}_{\mathrm{ih}}-\overline{\mathrm{w}}_{\mathrm{i}}\right) \cdot\left(\frac{\Delta \mathrm{p}_{\mathrm{ih}}}{\mathrm{p}_{\mathrm{ih}}}-\frac{\overline{\Delta \mathrm{p}_{\mathrm{i}}}}{\mathrm{p}_{\mathrm{i}}}\right)
\end{aligned}
$$

where $\bar{w}_{i}$ is the average across all households of the share of item i in total

consumption, and $\frac{\overline{\Delta \mathrm{p}_{\mathrm{i}}}}{\mathrm{p}_{\mathrm{i}}}$ is the average across all households (effectively, across all regions since I don't have within-region price variation) of depreciation-induced price changes. The first term in this decomposition is the compensating variation for a hypothetical household facing average price changes and having average expenditure shares. The value of this is 7.5 percent which is (almost) the mean effect, and is the same across households. The remaining terms vary across households and isolate the different sources of cross-household variation in the estimated compensating variation. The first of these captures cross-household variation due to cross-household differences in price changes (since it holds the expenditure shares fixed for all households). The second captures differences due to cross-household differences in expenditure shares, keeping price changes constant, and the third term captures purely household- and price-specific variation. The standard deviation across households of these three components are 0.6 percent, 1.5 percent, and 0.3 percent. This suggests that crosshousehold differences in expenditure shares are the most important source of crosshousehold differences in the welfare effects of the depreciation, while price differences (across regions, in our case) are less important, but still non-trivial.

I next examine the poverty impacts of these price changes. To do this, I begin with the 2000 distribution of expenditure across households in Egypt. I then subtract from each household the direct estimate of the compensating variation to arrive at a counterfactual distribution of expenditure which reflects the losses due to the subsequent depreciation. I then calculate the change in the headcount measure of poverty between these two distributions, for Egypt as a whole, and by regions. The results are summarized in Table 5. The first column provides the benchmark estimates 
of the headcount for 2000 , by region. The figures report the percent of households falling below the household-specific poverty lines calculated by El-Laithy, Lokshin, and Banerji (2003). The second column uses the same poverty lines, but replaces the actual distribution of expenditure with the counterfactual distribution reflecting the welfare losses due to the depreciation, and the third column reports the difference between the two. For Egypt as a whole, the estimated welfare effects of the depreciation can be interpreted as raising the headcount measure of poverty by 5 percentage points. The effects are lower in the major metropolitan centers of Egypt, with poverty increasing by 2 percent from a low base. Rural areas of Egypt saw the largest absolute increase in the headcount of 6.4 and 6.7 percent in lower and upper Egypt respectively, but from a much higher base. Not surprisingly, the ranking of poverty impacts across regions is quite similar to the ranking of welfare effects across regions in Table 4. The final column of Table 5 shows the actual headcounts by region in 2005 for reference. It is interesting to note that the estimated poverty impacts of exchange-rate-induced changes in consumer prices are substantial when compared with the overall change in poverty between 2000 and 2005.

I finally consider the role of substitution effects in response to the price changes induced by the depreciation. In order to implement Equations (14) and (15) I need information on changes over time on spending on each of the 20 expenditure items. Although I have access to the 2000 and 2005 household surveys, unfortunately these are not true panels but repeated cross-sections. I therefore employ cohort techniques to estimate the changes in spending shares, and from this the substitution effects. In particular, for the 2000 and 2005 household survey I construct cohorts based on four education categories, five age categories, and seven regional categories, for a total of 140 cohorts. For each cohort I calculate the average spending shares across the 20 expenditure items in the 2000 and 2005 surveys. Using the household-level variation within each cohort in the 2000 survey, I also estimate cohort-specific income elasticities for each expenditure share. Finally, I combine these ingredients with our estimates of the depreciation-induced price changes, to estimate the substitution effect.

The results of this exercise are summarized in Figure 7, which plots the estimated direct and substitution components of the compensating variation against log total expenditure at the cohort level. The estimates of the direct effect at the cohort level 
is quite similar to what I estimated at the household level, except that unsurprisingly there is less variation given that I now have data only for 140 cohorts that by construction are more homogenous in their spending shares than the underlying data. The more interesting point is the comparison of the relative magnitudes of the direct and substitution effects, with the latter much smaller (in absolute value) than the former. The mean (across cohorts) substitution effect is just -0.2 percent of initial expenditure, as compared with a mean (across cohort) direct effect of 6.6 percent of initial expenditure. This suggests that substitution effects are small, and the bulk of the welfare effect of the price changes is picked up by the direct effects that we have already discussed.

Clearly this estimate of the substitution effects is just an approximation, and one might ask whether it is reasonable to find such small substitution effects. Two factors suggest that these small estimates may not be too far from the truth. The first is simply the fairly coarse level of aggregation at which data limitations force us to carry out the analysis. Concretely, the scope households have for substituting between, say, food and rent, is much smaller than it is for substituting between higher or lower quality in the purchase of a particular food item. While such substitution undoubtedly occurs, it is not something that we are going to be able to pick up at this level of aggregation. We also note that Friedman and Levinsohn (2002), who use more finely disaggregated set of 155 food items and 64 non-food items, find much larger substitution effects that offset on average between one-third and one-half of the direct effects. However, these authors also argue that their estimates are probably an extreme upper bound on the magnitude of the substitution effects.

One might nevertheless worry that assuming zero cross-elasticiticies of substitution is driving the results. Recall that this assumption was necessitated by the fact that the quantity changes we observe in the panel are responses to the full set of price changes observed between 2000 and 2005, and not just the depreciation-induced price changes. I can however calculate the income and substitution effects associated with the full set of observed price changes over this period, and then the calculation of the latter will not require any assumptions about cross-elasticities of substitution (recall Equation (13) and the discussion immediately below). I have done this, and for this full set of price changes, at this fairly coarse level of aggregation, I find that the substitution effects are still very small relative to the direct effects. While these two calculations are 
not strictly comparable because they refer to different sets of price changes, they do suggest that the scope for substitution is lower at coarser levels of disaggregation.

\section{Conclusions}

This paper has empirically investigated the welfare effects of the large depreciation in Egypt between 2000 and 2005 operating through exchange-rate induced changes in consumer prices. I find a significant, and very heterogenous across products, degree of pass-through from the exchange rate to consumer prices. On average, the welfare cost of these price changes was 7.4 percent of households' initial expenditure. Since estimated pass-through for food items was significantly greater than for non-food items, the effects of the depreciation disproportionately affected poor households.

One should however keep in mind three major caveats about these results. The first is that I have looked only at the effects of the exchange rate working through consumer prices. The depreciation is also likely to have had heterogenous impacts on the earnings of households employed in different sectors, and these effects are not capture for lack of (a) detailed information in the household survey of the sector of employment of households, and (b) evidence on the effects of exchange rate changes on wages across sectors in Egypt.

A second limitation is that data limitations have also forced me to work at a fairly high level of aggregation. At this coarse level of aggregation, estimated substitution effects in response to price changes are small, and so I am likely to be overestimating the effects on household welfare. Consider for example the study of the Indonesian depreciation of 1997 by Friedman and Levinsohn (2002). They worked with a much more highly disaggregated set of expenditure items, and found that substitution effects were roughly half the size of the direct effects. If similar substitution behavior occurred for households in Egypt in response to the (much smaller) set of price changes, but was missed at the coarse level of aggregation at which I have worked, then the adverse welfare effects of the depreciation will be considerably overstated and could be much smaller. 
Finally, as noted in the introduction, I have studied the welfare effects of depreciation-induced changes in consumer prices over a fairly short period with a fairly large depreciation, and this time horizon drives the finding of significant welfare losses. It is important to note that the depreciation in the trade-weighted nominal exchange rate between 2000 and 2005 was preceded by an even larger trade-weighted nominal appreciation in the previous five years between 1995 and 2000, and that over the entire period between 1995 and 2005, the trade-weighted nominal exchange rate appreciated by about 20 percent. If the pattern of exchange rate pass-through to disaggregated consumer prices was similar during this earlier period, then one can interpret the welfare losses sustained between 2000 and 2005 as just a partial reversal of the welfare gains experienced during the appreciation between 1995 and 2000. 


\section{References}

Burstein, Ariel, Martin Eichenbaum, and Sergio Rebelo (2005). "Large Devaluations and the Real Exchange Rate". Journal of Political Economy. 113(4):742-784.

Campa, Jose Manuel and Linda S. Goldberg (2005). "Exchange Rate Pass-through Into Import Prices". Review of Economics and Statistics. 87(4):679-690.

Campa, Jose Manuel and Linda S. Goldberg (2006). "Distribution Margins, Imported Inputs, and the Sensitivity of the CPI to Exchange Rates". Manuscript, Federal Reserve Bank of New York (http://www.newyorkfed.org/research/economists/goldberg/)

Chen, Shaohua and Martin Ravallion (2004). "Welfare Impacts of China's Accession to the World Trade Organization". World Bank Economic Review. 18(1):29-57.

Choudri, Ehsan and Dalia Hakura (2001). "Exchange Rate Pass-Through to Domestic Prices: Does the Inflationary Environment Matter?" IMF Working Paper No. 01/194.

Deaton, Angus (1988). "Quality, Quantity and Spatial Variation of Price". American Economic Review. 78(3):418-431.

Deaton, Angus (1990). "Price Elasticities from Survey Data: Extensions and Indonesian Results". Journal of Econometrics. 44(3):281-309.

El-Laithy, Heba, Michael Lokshin and Arup Banerji (2003). "Poverty and Economic Growth in Egypt". World Bank Policy Research Department Working Paper Number 3068.

Frankel, Jeffrey, David Parsley and Shang-Jin Wei (2005). "Slow Pass-through Around the World: A New Import for Developing Countries?". NBER Working Paper No. 11199.

Ferreira, Franciso, Phillippe Leite, Luiz Pereira da Silva, and Paolo Picchetti (2004). "Can the Distributional Impact of Macroeconomic Shocks be Predicted? A Comparison of the Performance of Macro-Micro Models with Historical Data for Brazil".

Freidman, Jed and James Levinsohn (2002). "The Distributional Impacts of Indonesia's Financial Crisis on Household Welfare: A "Rapid-Response" Methodology". World Bank Economic Review. 16(3):397-423.

Vartia, Yrjo (1983). "Efficient Methods of Measuring Welfare Change and Compensated Income In Terms of Ordinary Demand Functions". Econometrica. 51(1):79-98. 


\begin{tabular}{|lcccccccc|}
\hline $\begin{array}{l}\text { Table 1 -- Exchange Rates and Consumer Prices, 2000-2005 } \\
\text { (Annual Change, December over December) }\end{array}$ \\
\hline \\
\hline
\end{tabular}




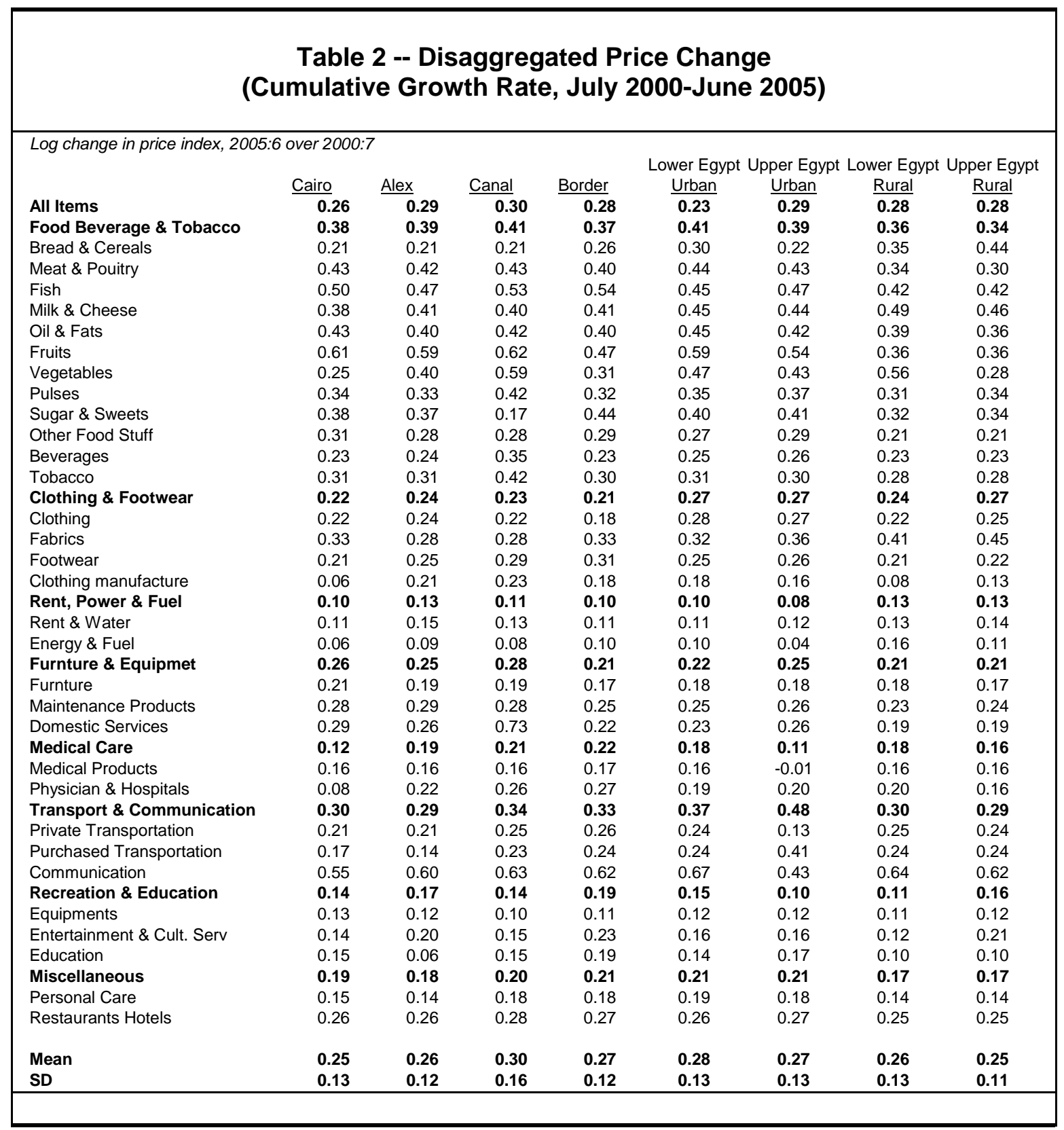




\begin{tabular}{|c|c|c|c|}
\hline \multicolumn{4}{|c|}{$\begin{array}{c}\text { Table } 3 \text {-- Summary Statistics on Pass-Through Estimates } \\
\text { and Price Changes }\end{array}$} \\
\hline & $\begin{array}{l}\text { Actual Price Change } \\
\text { 2000:7 - 2005:6 }\end{array}$ & $\begin{array}{c}\text { Estimated Pass-Through } \\
\text { Coefficient }\end{array}$ & $\begin{array}{l}\text { Estimated Share of Price } \\
\text { Change Due to Devaluation }\end{array}$ \\
\hline \multicolumn{4}{|l|}{ Overall } \\
\hline 25th Percentile & 0.21 & 0.05 & 0.06 \\
\hline 50th Percentile & 0.28 & 0.19 & 0.19 \\
\hline 75th Percentile & 0.40 & 0.47 & 0.34 \\
\hline \multicolumn{4}{|l|}{ Food } \\
\hline 25th Percentile & 0.28 & 0.30 & 0.20 \\
\hline 50th Percentile & 0.37 & 0.43 & 0.31 \\
\hline 75th Percentile & 0.43 & 0.63 & 0.46 \\
\hline \multicolumn{4}{|l|}{ Non-Food } \\
\hline 25th Percentile & 0.15 & -0.03 & -0.03 \\
\hline 50th Percentile & 0.21 & 0.07 & 0.10 \\
\hline 75th Percentile & 0.26 & 0.15 & 0.18 \\
\hline
\end{tabular}




\begin{tabular}{|c|c|c|c|c|c|c|c|}
\hline \multicolumn{8}{|c|}{$\begin{array}{l}\text { Table } 4 \text {-- Estimated Compensating Variation, } \\
\text { by Region and Quintile of Expenditure Distribution }\end{array}$} \\
\hline & \multirow[b]{2}{*}{ Mean } & \multirow[b]{2}{*}{ Std.Dev. } & \multicolumn{5}{|c|}{ Mean by Quintile of Expenditure Distribution } \\
\hline & & & Lowest & Second & Third & Fourth & Highest \\
\hline All Egypt & 0.074 & 0.015 & 0.081 & 0.077 & 0.075 & 0.073 & 0.065 \\
\hline Metropolitan & 0.072 & 0.016 & 0.083 & 0.077 & 0.073 & 0.069 & 0.055 \\
\hline Cairo & 0.071 & 0.018 & 0.084 & 0.077 & 0.073 & 0.068 & 0.052 \\
\hline Alexandria & 0.070 & 0.015 & 0.080 & 0.075 & 0.072 & 0.068 & 0.057 \\
\hline Canal & 0.077 & 0.014 & 0.086 & 0.081 & 0.079 & 0.075 & 0.066 \\
\hline Border & 0.067 & 0.013 & 0.072 & 0.068 & 0.068 & 0.066 & 0.062 \\
\hline Lower Egypt Urban & 0.072 & 0.013 & 0.077 & 0.074 & 0.073 & 0.071 & 0.064 \\
\hline Upper Egypt Urban & 0.072 & 0.015 & 0.079 & 0.075 & 0.074 & 0.071 & 0.061 \\
\hline Lower Egypt Rural & 0.084 & 0.013 & 0.088 & 0.085 & 0.085 & 0.083 & 0.080 \\
\hline Upper Egypt Rural & 0.070 & 0.010 & 0.073 & 0.071 & 0.070 & 0.069 & 0.066 \\
\hline
\end{tabular}




\begin{tabular}{|c|c|c|c|c|}
\hline \multicolumn{5}{|c|}{ Table 5 -- Poverty Impacts of Depreciation-Induced Price Changes } \\
\hline & \multicolumn{4}{|c|}{ Headcount Measure of Poverty (Percent of Households) } \\
\hline & & Counterfactual With & & \\
\hline & 2000 Actual & Devaluation Only & Difference & 2005 Actual \\
\hline All Egypt & 16.7 & 21.8 & 5.0 & 19.6 \\
\hline Metropolitan & 5.1 & 7.1 & 2.0 & 5.7 \\
\hline Cairo & 5.0 & 6.9 & 1.9 & 4.6 \\
\hline Alexandria & 6.2 & 8.3 & 2.1 & 8.0 \\
\hline Canal & 3.4 & 5.7 & 2.2 & 5.7 \\
\hline Border & 9.9 & 12.5 & 2.6 & 14.5 \\
\hline Lower Egypt Urban & 6.5 & 9.4 & 3.0 & 9.2 \\
\hline Upper Egypt Urban & 19.3 & 24.0 & 4.7 & 18.6 \\
\hline Lower Egypt Rural & 11.8 & 18.2 & 6.4 & 16.8 \\
\hline Upper Egypt Rural & 34.2 & 40.8 & 6.7 & 39.1 \\
\hline
\end{tabular}


Figure 1-- Exchange Rates and Consumer Prices, 1995-2005

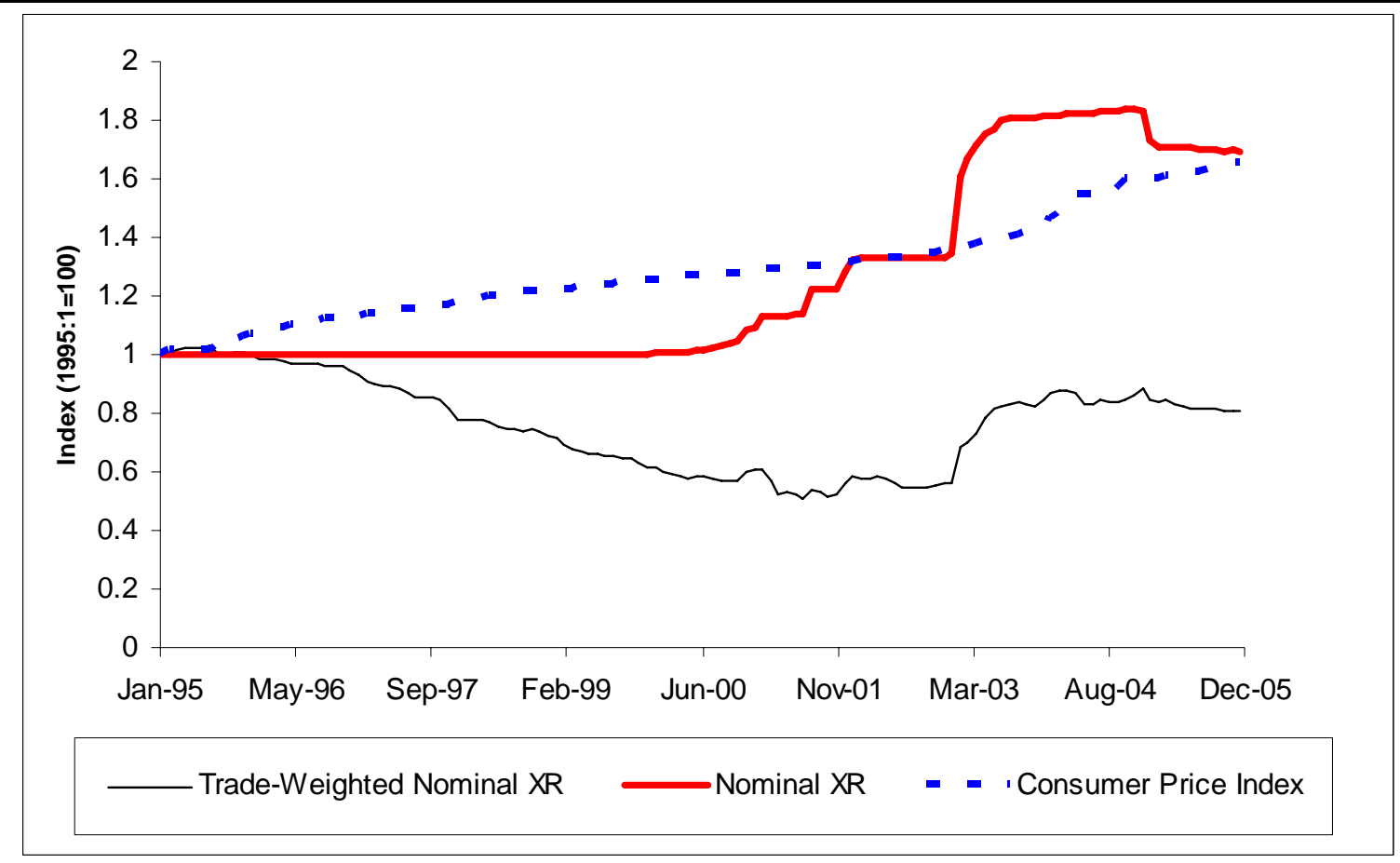




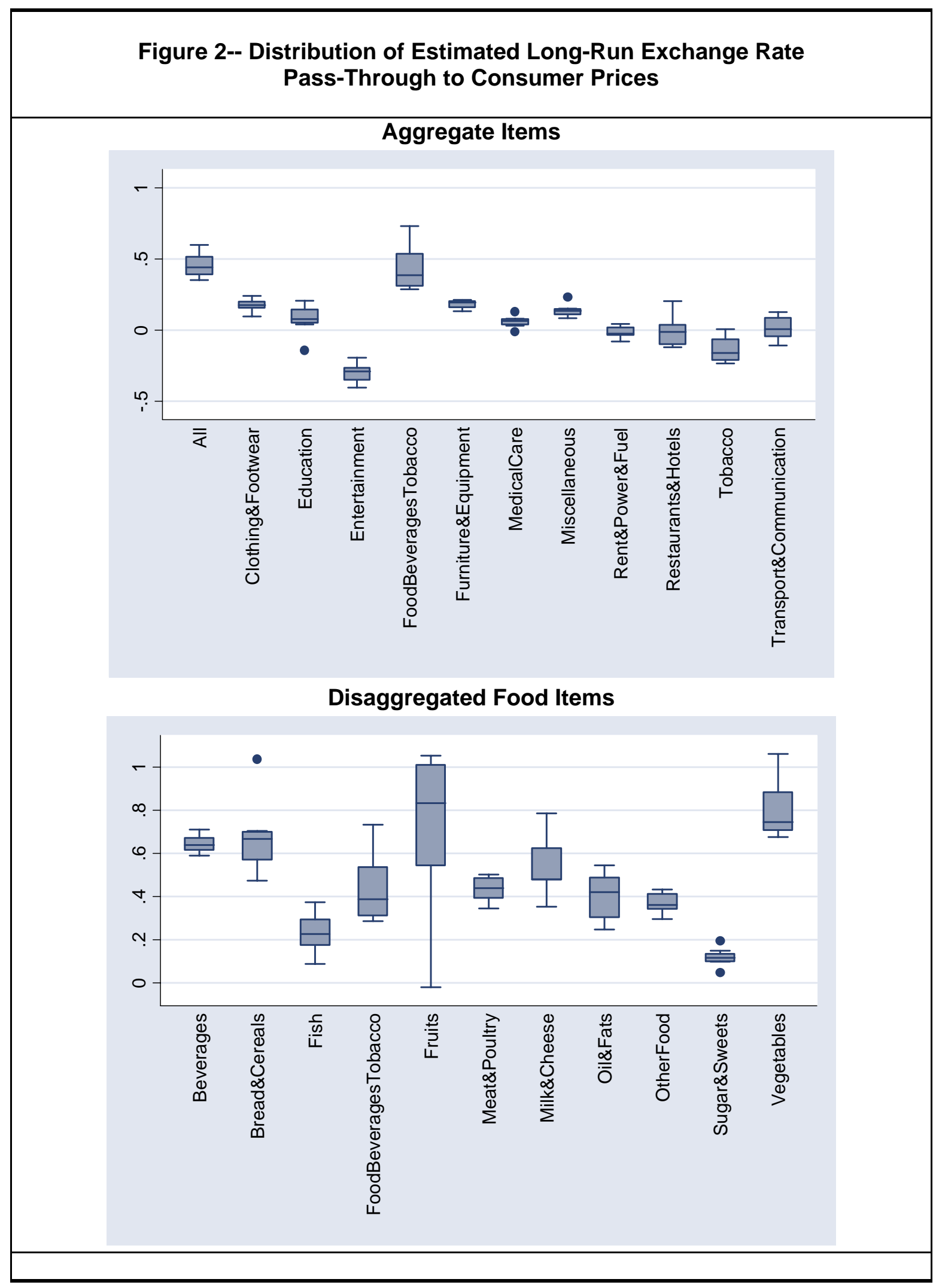


Figure 3-- Distribution of Significance of Estimated Long-Run Exchange Rate Pass-Through to Consumer Prices

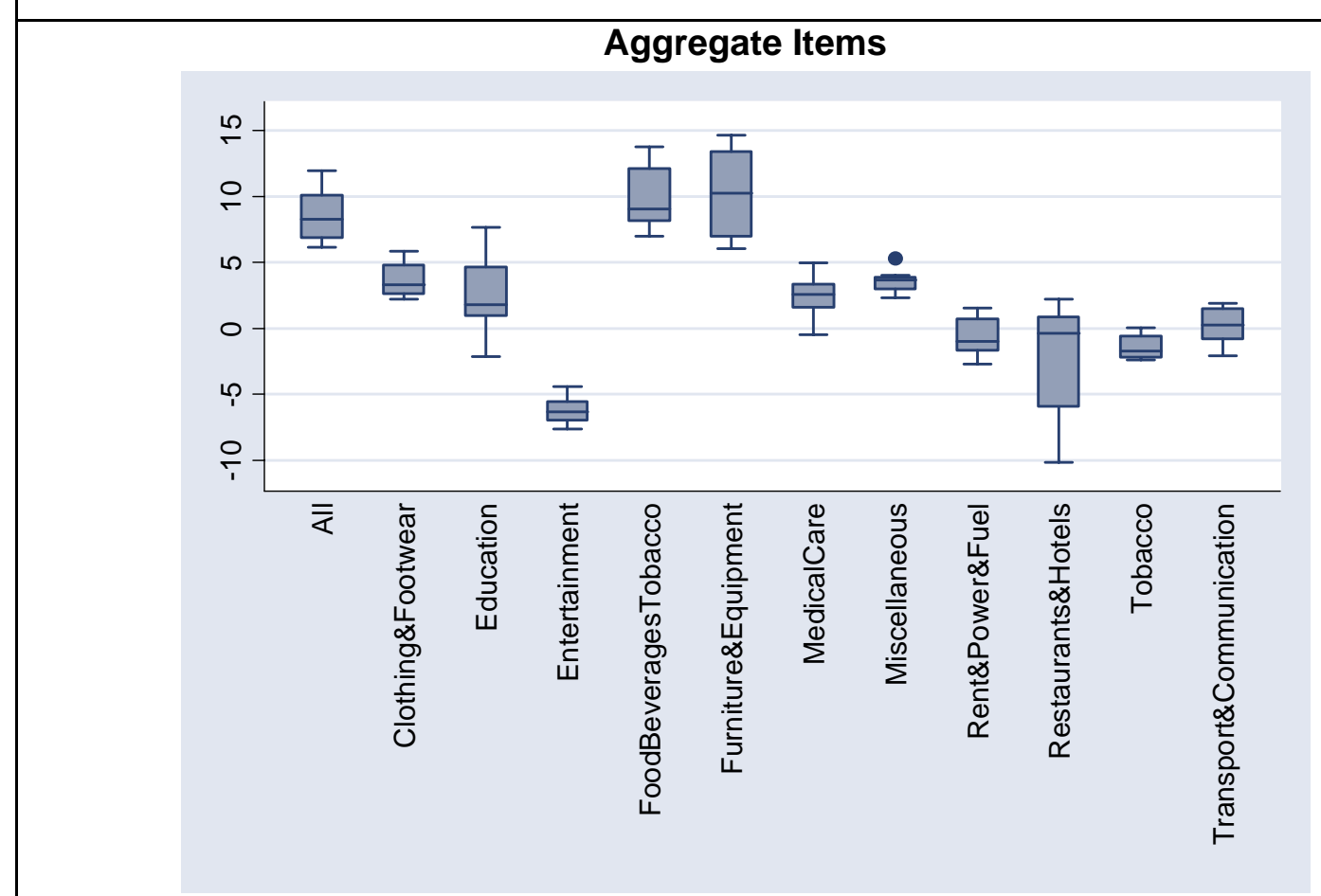

\section{Disaggregated Food Items}

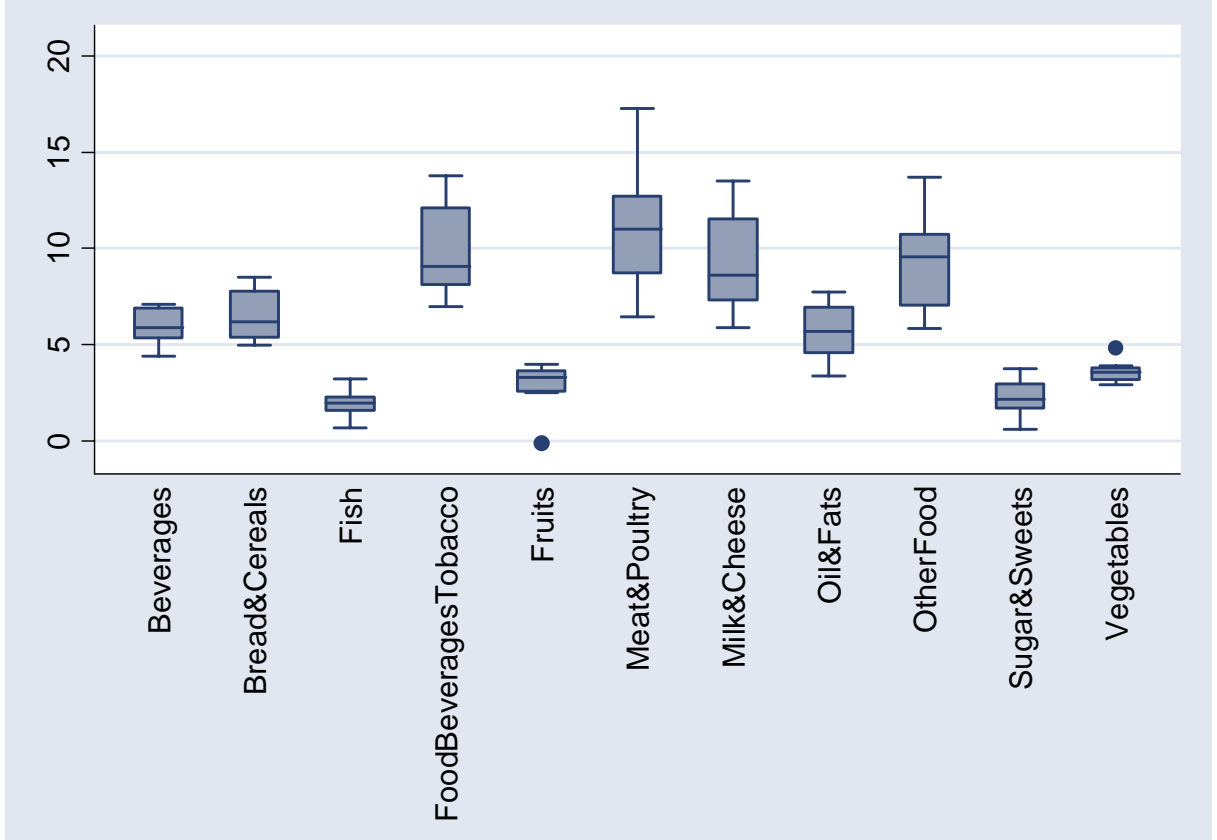


Figure 4-- Distribution of Share of Observed Price Changes 2000-2005 Due to the Exchange Rate Depreciation

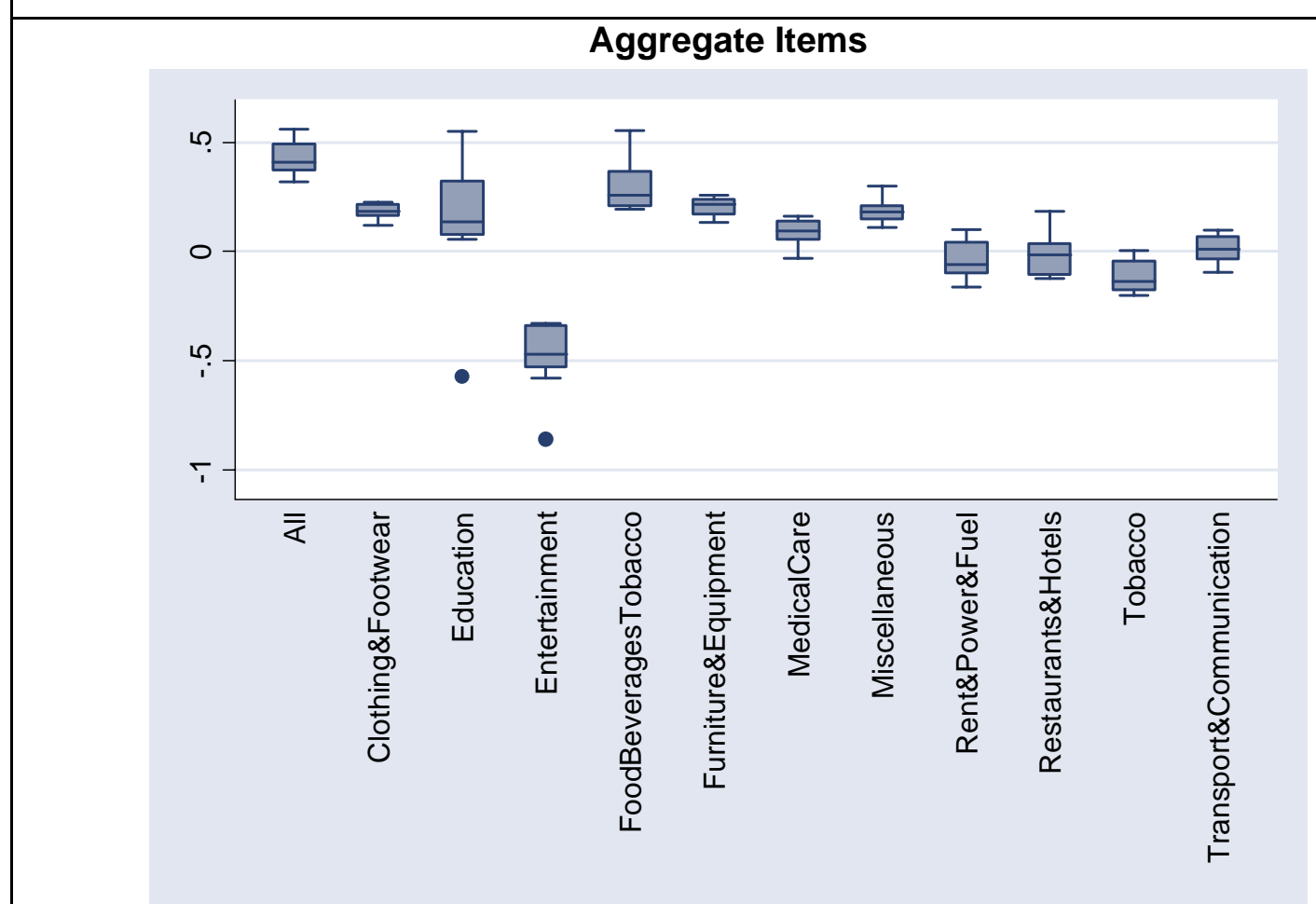

Disaggregated Food Items

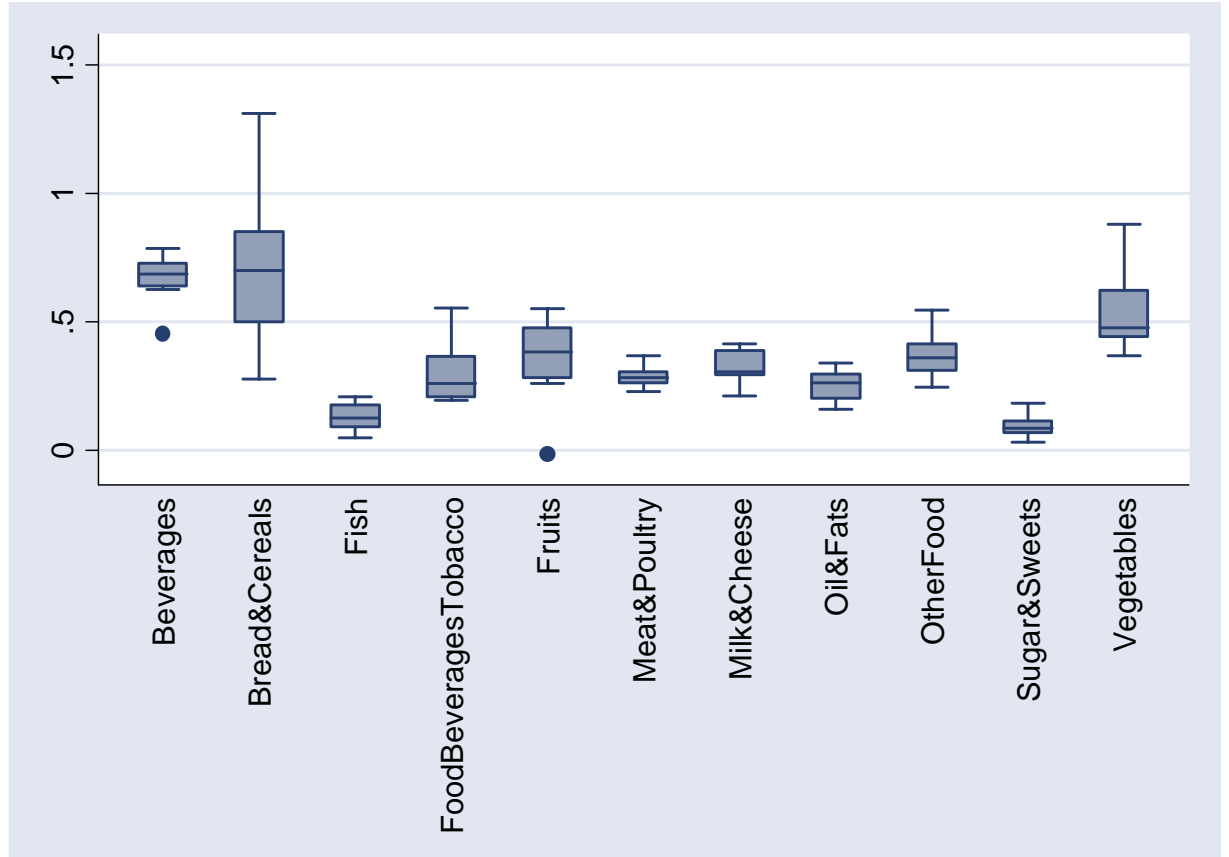




\section{Figure 5-- Direct Effects of Price Changes on Welfare}

(Compensating Variation Calculated as Percent Change in Total Expenditure Required to Purchase Initial Consumption Basket)

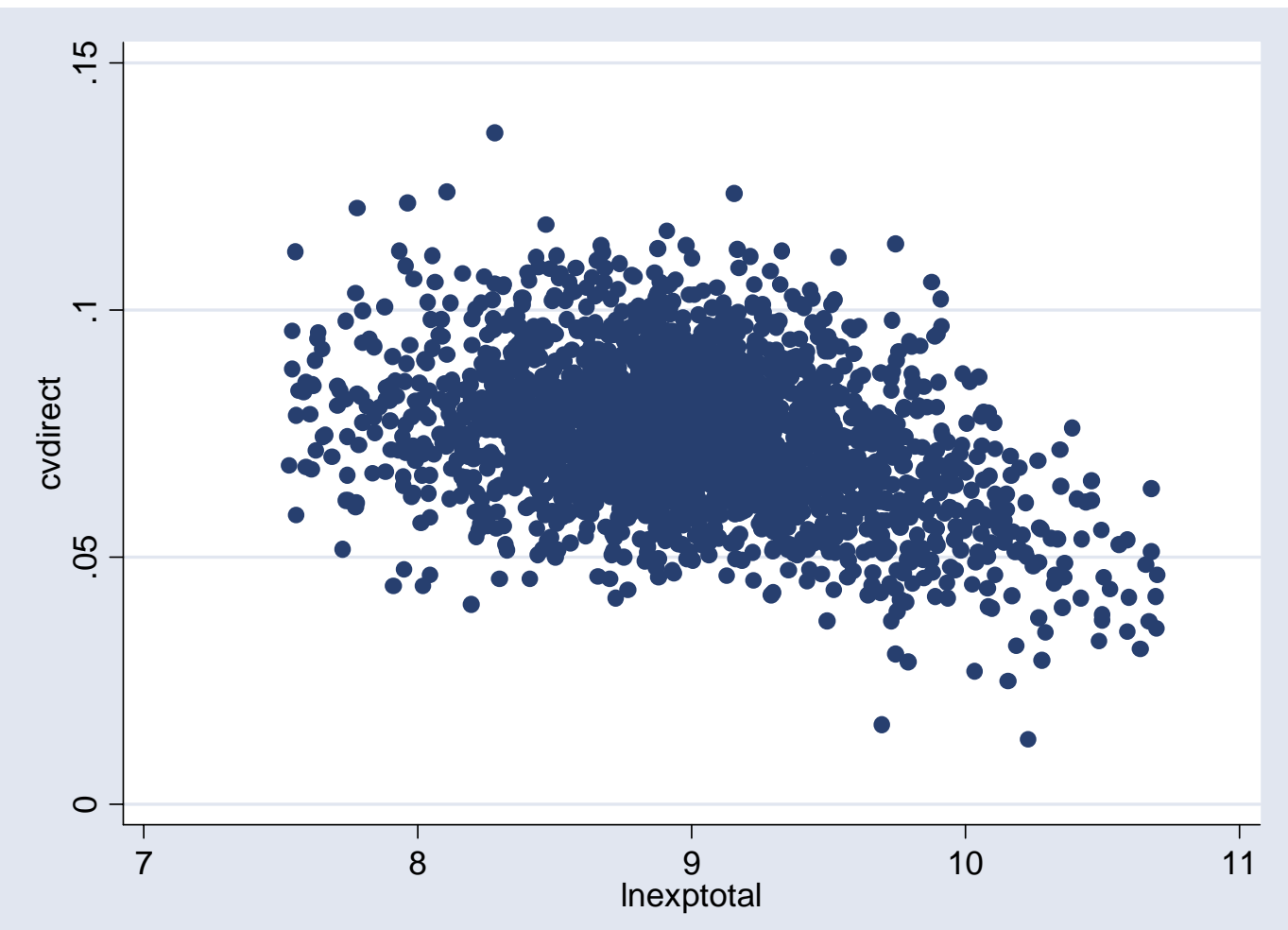




\section{Figure 6-- Direct Effects of Price Changes on Welfare}

(Compensating Variation Calculated as Percent Change in Total Expenditure Required to Purchase Initial Consumption Basket, Rolling Average of 100 Households Ranked by Total Expenditure)

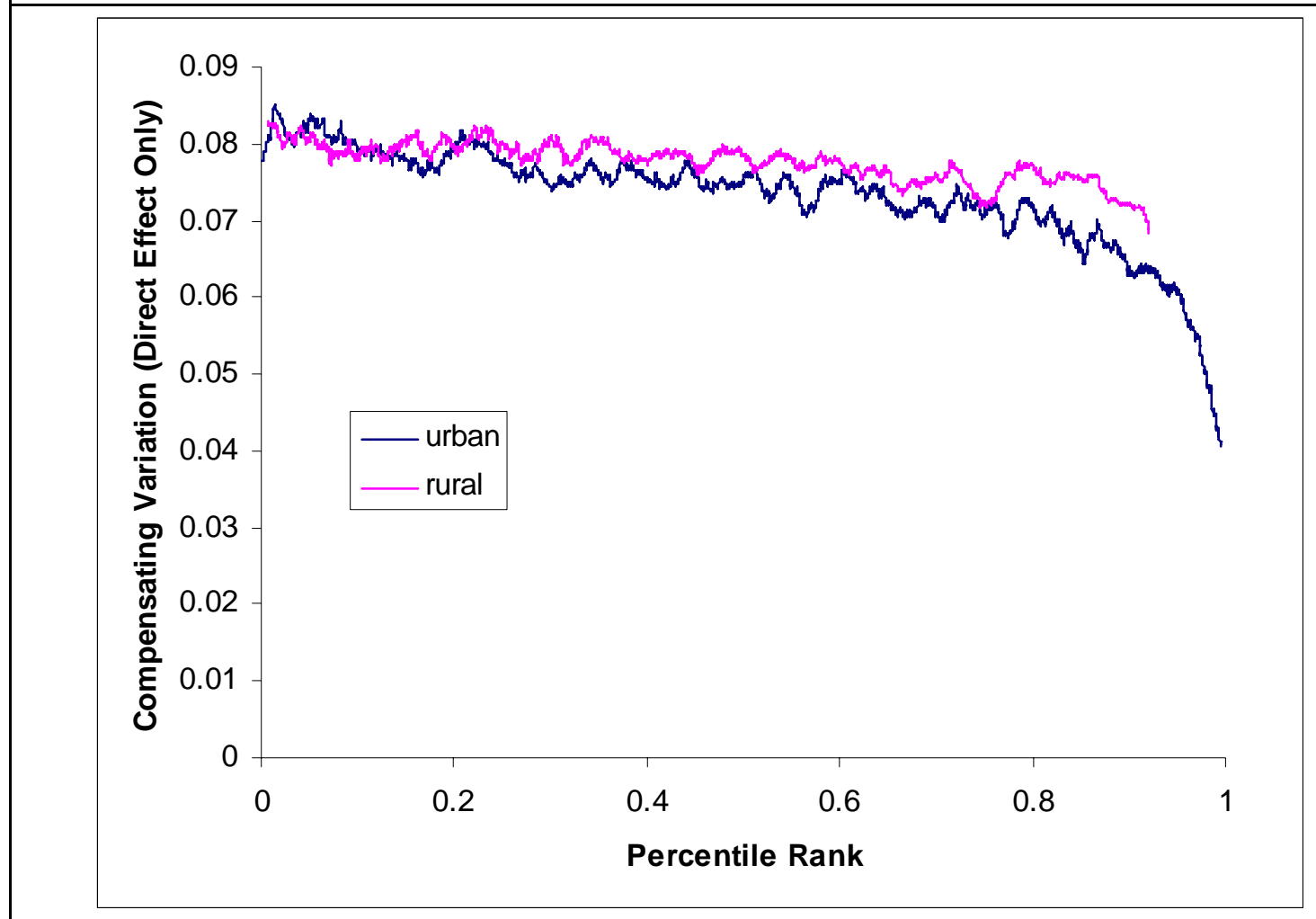




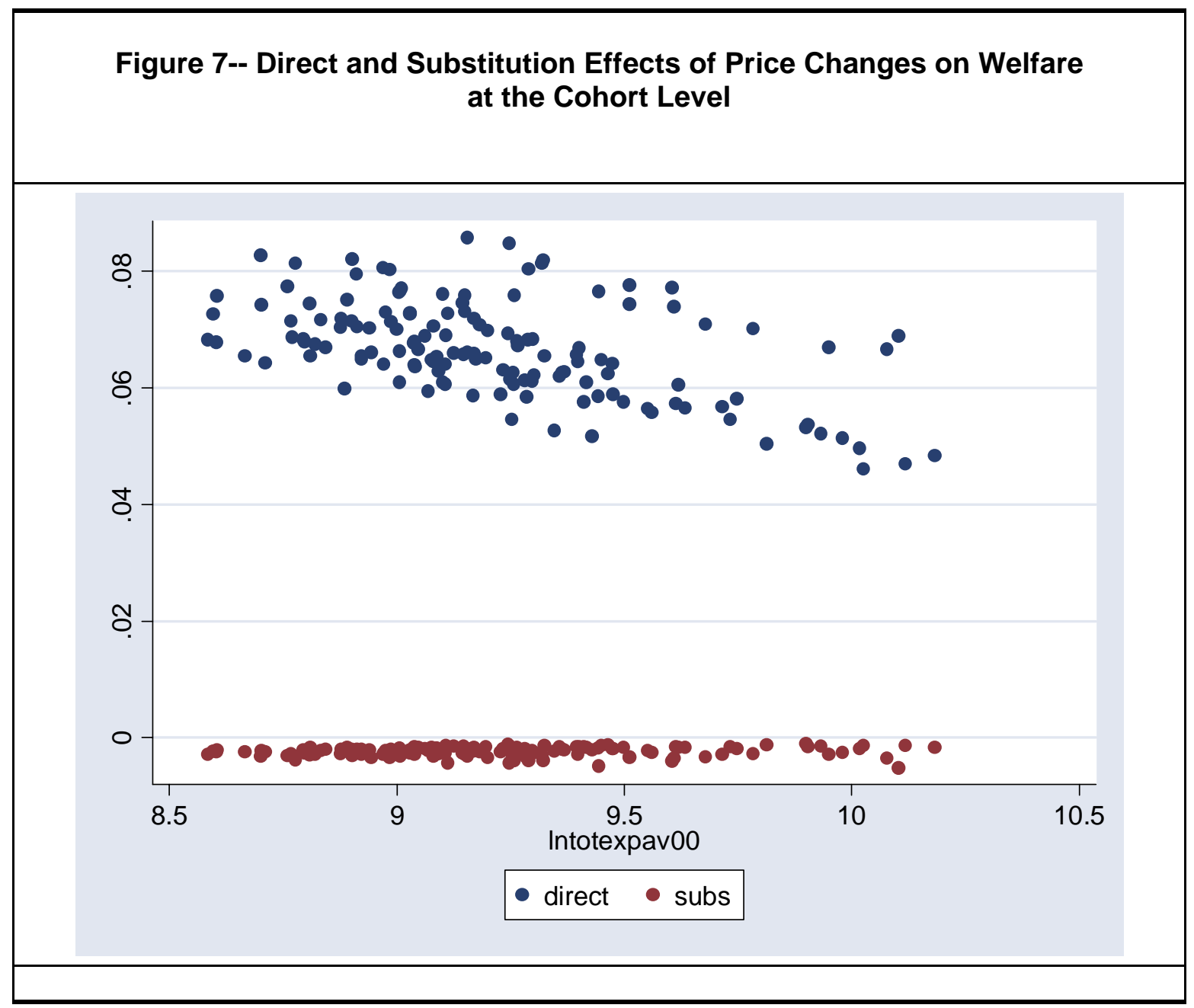

